\title{
Reduction in right ventricular pressure and/or volume overload by percutaneous pulmonary valve implantation improves tricuspid valve function as assessed by $M R$ imaging
}

\author{
Philipp Lurz*1, Vivek Muthurangu², Silvia Schievano ${ }^{2}$, \\ Sachin Khambadkone ${ }^{2}$, Marina Hughes ${ }^{2}$, Philipp Bonhoeffer ${ }^{2}$ and \\ Andrew Taylor ${ }^{2}$
}

Address: ${ }^{1}$ UCL Institute of Child Health, London, UK \& Heart Centre Leipzig, Leipzig, Germany and ${ }^{2}$ UCL Institute of Child Health, London, UK * Corresponding author

from 13th Annual SCMR Scientific Sessions

Phoenix, AZ, USA. 21 -24 January 2010

Published: 21 January 2010

Journal of Cardiovascular Magnetic Resonance 2010, I2(SuppI I):P4 doi:I0.I I86/1532-429X-I2-SI-P4

This abstract is available from: http://jcmr-online.com/content/I2/SI/P4

(c) 2010 Lurz et al; licensee BioMed Central Ltd.

\section{Introduction}

Percutaneous pulmonary valve implantation (PPVI) is a less invasive strategy to treat right ventricle (RV) to pulmonary artery (PA) dysfunction. However, in contrast to surgery, concomitant tricuspid valve lesions cannot be treated with this technique.

\section{Purpose}

In this study we analysed the incidence of significant tricuspid regurgitation in patients with RV to PA conduit dysfunction and the impact of PPVI on tricuspid valve function

\section{Methods}

Magnetic resonance (MR) imaging including biventricular volumes and great vessel blood flow assessment was performed prior to and immediately after PPVI in 137 patients. Retrospectively, out of this patient population, we selected patients who had a tricuspid regurgitation fraction (TRF) $>10 \%$ on MR prior to valve implantation. TRF was calculated from right ventricular stroke volume and pulmonary artery forward flow.

\section{Results}

A TRF $>10 \%$ was seen in 17 patients prior to PPVI (incidence $12.4 \%$ ). Patients with a TRF $>10 \%$ had a significantly higher RV enddiastolic volume than patients with preserved tricuspid valve function $(142.7 \pm 34.4$ vs 108.7 $\pm 37.0 \mathrm{ml} / \mathrm{m} 2 ; \mathrm{p}<0.001$ ).

After PPVI, the gradient across the conduit fell from 40.8 $\pm 12.4 \mathrm{mmHg}$ to $15.9 \pm 5.3 \mathrm{mmHg}(\mathrm{p}<0.001)$. In addition, there was a decrease in RV end-diastolic volumes $(113.3 \pm 20.8 \mathrm{ml} / \mathrm{m} 2$ to $89.3 \pm 19.6 \mathrm{ml} / \mathrm{m} 2, \mathrm{p}<0.001)$ and pulmonary regurgitation fraction $(16.6 \pm 14.6 \%$ to $1.9 \pm 2.7 \%, \mathrm{p}<0.024)$ on MR. Reduction in RV pressure and/or volume overload was associated with a significant reduction in TRF $(18.5 \pm 6.7 \%$ to $8.9 \pm 6.7 \%, \mathrm{p}=0.02)$.

\section{Conclusion}

Significant tricuspid regurgitation in the context of RV to PA conduit dysfunction is not common. Further, relief in RV volume and pressure overload by PPVI improves tricuspid valve function acutely. This is important, when patients are selected for either surgical or percutaneous treatment of RV to PA conduit dysfunction. 